América sin nombre, n. ${ }^{\circ} 22$ (2017) 107-114

DOI 10.14198/AMESN.2017.22.10

ISSN: 1577.3442 / eISSN: 1989-9831

Fecha de recepción: 05/06/2017

Fecha de aceptación: 02/07/2017
Puede citar este artículo como:

Buxó, José Pascual. «Juan Rulfo: los principios de una nueva poética narrativa». El cuento hispanoamericano del siglo XXI. Agustín Prado Alvarado (coordinador). América sin Nombre, 22 (2017): 107-114, DOI: 10.14198/ AMESN.2017.22.10

Link para este artículo: http://dx.doi.org/10.14198/AMESN.2017.221.10

\title{
Juan Rulfo: los principios de una nueva poética narrativa
}

\author{
Juan Rulfo: the principles of a new poetic narrative
}

\author{
José Pascual Buxó* \\ Universidad Nacional Autónoma de México
}

\section{Resumen}

El artículo revisa el nuevo modo del quehacer narrativo que supuso la irrupción de Juan Rulfo en el panorama de las letras mexicanas, analizando algunas cuestiones axiales de su obra, como la ausencia absoluta de la figura del autor-narrador, la singularidad de las voces de los personajes o la creación de mundos narrativos propios, a partir del análisis de algunos fragmentos de los cuentos iniciales «Nos han dado la tierra» y «Macario», publicados en 1945 en la revista Pan, de Guadalajara.

Palabras clave: Juan Rulfo, Nos han dado la tierra, Macario, El desafío de la creación, narrativa mexicana

\begin{abstract}
The article reviews the new way that led to the emergence of Juan Rulfo's narrative in the panorama of Mexican letters, analyzing some of the axial issues of his work, such as the absolute absence of the author-narrator figure, the uniqueness of the voices of the characters or the creation of his own narrative worlds, from the analysis of some fragments of the initial stories «Nos han dado la tierra» and «Macario», published in 1945 in Pan magazine, from Guadalajara.
\end{abstract}

Keywords: Juan Rulfo, Nos han dado la tierra, Macario, El desafío de la creación, Mexican narrative

\footnotetext{
* Investigador incansable, su extensa obra abarca la literatura, la historia, el pensamiento y el arte principalmente de México, pero también de Espańa y América Latina. Sus estudios sobre la literatura y la cultura novohispana son hoy referencias imprescindibles para los investigadores nacionales y extranjeros. Y es que ésta ha sido una de las vigas maestras de su trabajo de investigación. El libro Góngora en la poesía novohispana (México, UNAM, 1960) fue un trabajo pionero en la revaloración de la poesía colonial, continuando la línea de Alfonso Reyes y Alfonso Méndez Plancarte, pero, por primera vez, sobre la base de un minucioso análisis estilístico que revela a los poetas novohispanos como recreadores (o como diría luego Ángel Rama, como transculturadores) y no como simples imitadores. De esa época es su libro Arco y certamen de la poesía mexicana colonial (Universidad Veracruzana, 1959) anticipo de las monografías que habrán de venir después, y que hoy día son fuente documental de primer orden para la historia de la vida social y cultural del virreinato. Poco tiempo después aparece su bellísimo libro Muerte y desengaño en la poesía novohispana (México, UNAM, 1975).
} 
$\mathrm{Al}$ conmemorarse los cien años de su nacimiento y los sesenta cumplidos de la publicación de El llano en llamas (1953) y de Pedro Páramo (1955), ¿qué más podría decirse que ya no se haya dicho en la vastísima bibliografía crítica dedicada a Juan Rulfo? ${ }^{1}$ Desde su misma aparición se hizo patente que nos hallábamos ante la evidencia de un nuevo modo, sorprendente y exacto, de concebir la naturaleza y el sentido de las narraciones literarias.

Habituados al carácter testimonial propio de las novelas inspiradas en tipos y sucesos de la Revolución mexicana, no dejó de inquietar a sus primeros lectores la sutil evocación de ciertas realidades humanas que, aun siendo fácilmente reconocibles en el mundo rural mexicano, se distanciaban expresamente -en estilo, tono y construcción narrativa- de los habituales paradigmas de la novela documentalista y patriótica. ¿Cuál era la intención del autor al renunciar a toda injerencia elocutiva que sirviera para «llevar de la mano" al lector a la revelación del ser y las circunstancias de sus personajes, y cuál era su propósito al hacer que éstos asumieran por sí mismos -como en un soliloquio ensimismado- la manifestación de las pesadumbres de su conciencia?

Confrontados de manera tan patente con el modelo "monológico» ${ }^{2}$ a que estaban habituados los lectores mexicanos de las primeras décadas del siglo $\mathrm{xx}$, los dos primeros cuentos de un joven escritor jalisciense publicados en $1945^{3}$ ya contenían - para quien supiera verlo sin prejuicios- todas las características compositivas y los principios estético-literarios que le

1. No pretende este trabajo revisar la bibliografía crítica sobre Rulfo, en constante producción. Entre otros, un volumen colectivo reciente, 60 años de el Llano en llamas: reflexiones académicas (2015) editado por Alberto Vital, María Esther Guzmán y Stella Cuéllar y publicado por el Instituto de Investigaciones Filológicas de la UNAM revisa y actualiza esta cuestión en El llano en llamas. En otros trabajos, citados en la bibliografía, abordé el análisis de la narrativa de Rulfo.

2. En términos de Bajtín, «monológico» alude al relato «estructurado como la totalidad de una conciencia que objetivamente abarca las otras», por contraposición a «dialógico» como la «total interacción de varias (conciencias), sin que entre ellas una llegue a ser objeto de la otra». Cf. Mijaíl Bajtín, Problemas de la poética de Dostoievski. Trad. de Tatiana Bubnova. Fondo de Cultura Económica, México, 1986.

3. «Nos han dado la tierra» $\mathrm{y}$ "Macario» aparecieron, respectivamente, en los números 2 (julio) y 6 (noviembre) de 1945 de la revista Pan, de Guadalajara. Las citas están extraídas de la edición de El llano en llamas (1986) de Carlos Blanco Aguinaga en la colección Letras Hispánicas. serían plenamente reconocidos ocho años más tarde, a raíz de la publicación de sus libros.

En un agudísimo y clarividente artículo publicado en 1955, Carlos Blanco Aguinaga reconocía sin ambages que en el cruce de todas las corrientes filosóficas, artísticas y literarias que fueron surgiendo a fines del siglo XIx y principios del xx, Juan Rulfo «va creando desde dentro con originalidad plena una realidad a la vez universal y moderna, tradicional y mexicana» (59) en un conjunto de obras que abren «nuevos derroteros para la prosa narrativa mexicana» (59). En efecto, esa nueva realidad artística a que nos enfrentaban los cuentos de Juan Rulfo, pudo resultar insólita y desconcertante para muchos críticos anclados en el doble modelo ideológico y literario del nacionalismo mexicano, para quienes existía una sola verdad histórica y un único tipo de representaciones literarias: las que se ajustan fielmente a unos hechos debidamente documentados y se vale de ciertos procedimientos discursivos a los que se atribuye -por tradición y por costumbre- la capacidad de suscitar en los lectores los deseables efectos de verosimilitud tanto de los acontecimientos narrados como de la entidad de sus protagonistas, cuya realidad se hace perceptible a través de la descripción de su aspecto físico y de las actitudes que tipifican su condición social y moral, procediendo en todo de conformidad con una visión naturalista o fotográfica, idealmente fundada en el registro directo de las personas y las cosas evocadas.

Pese a su pretendida objetividad, esa fiel evocación de los diferentes aspectos de la realidad humana y social no dejaba de fundarse en el empleo de ciertos procedimientos de larga tradición retórica convencionalmente identificados con el realismo literario, entre ellos, la prosopografía, la evidencia y la topografía o descripción visualizable de lugares y personas; la etopeya o relación de sus costumbres y comportamientos morales; la sermocinatio o reproducción de sus modos típicos de hablar. Sin embargo, la gran mayoría de los lectores formados en esa tradición canónica quizá no prestaran mayor atención al carácter artificioso y convencional de aquellos recursos discursivos a los que se atribuía la fidelidad de las representaciones artísticas respecto de sus hipotéticos referentes extra textuales, y asumirían los efectos de realidad suscitados por tales recursos como si el mismo lector se hallara ante la cabal contemplación de ciertos hechos perfectamente identificables a partir de su experiencia cotidiana.

Sin mengua de su destreza literaria ni de su notoria relevancia entre los novelistas de su generación, 
sirva de mínimo ejemplo de aquellas arraigadas convenciones discursivas la descripción hecha por Mariano Azuela en Las moscas (1918) de una expectante masa humana que aguarda la llegada del tren en que viaja un general revolucionario, cuyo apellido, Malacara, es todo un arquetipo de su catadura moral y un compendiado programa de su previsible comportamiento como gobernante:

Obsérvese un movimiento de agitación mayor entre la multitud. Una locomotora ha dado dos breves pitidos, la campana se mece acompasada, chocan los topes con estruendo y el tren retrocede y entra bajo la marquesina...

La multitud se repliega en dos alas. Negrean a lo lejos en apretado grupo los civiles y uno que otro militar. A medida que se acerca van perfilándose las encorvadas espaldas, los cuellos estirados, las caras adoratrices, todos en torno de una cabeza vigorosa que en sus toscos labios sin barba lleva una sonrisa de suprema indolencia (Azuela 260).

En pasajes como estos, se hace patente la figura del autor como sujeto de la enunciación de su relato, que es quien -desde una perspectiva unívoca- selecciona los elementos que resulten más significativos para la construcción de una estampa reconocible de ciertos ambientes y personajes, y escoge los epítetos que mejor se correspondan con los rasgos físicos y la condición moral del héroe: su cabeza es vigorosa; sus labios, toscos; su sonrisa indolente. Nada queda oculto al lector, que ya no tendrá que esforzarse en descubrir por sí mismo el verdadero carácter de aquel personaje, trazado, como quien dice, de un solo y definitivo plumazo.

Los lectores de «Nos han dado la tierra» que esperaran encontrar en ese y otros cuentos de Rulfo las mismas convenciones discursivas y los mismos presupuestos estéticos e ideológicos a los que les había acostumbrado la tradición del realismo social, pudieron sentirse confundidos y, en algunos casos, solemnemente irritados ante una nueva manera de narrar que no ocultaba su ruptura respecto de una tradición ciertamente anquilosada pero que, al promediar el siglo $\mathrm{xx}$ y ya en pleno auge de todas las vanguardias, aún seguía siendo entendida por muchos como la única recomendable y apropiada para dar razón de nuestras realidades históricas, psicológicas y sociales, que era -a su parecer-el principal cometido de toda obra literaria.

Dan testimonio de aquella actitudes beligerantes y reaccionarias un considerable número de publicaciones periodísticas en que se acusaba a Juan Rulfo de ser un escritor extranjerizante e inexplicablemente alejado de la magnífica tradición nacionalista, y todo ello a pesar de la indudable y esencial mexicanidad de sus temas, ambientes y personajes. Es ya del todo innecesario volver a esas malandanzas de la crítica mordaz, pero me sigue pareciendo oportuno precisar algunas de las causas que provocaron esa inicial incomprensión y rechazo de los cuentos y la novela de Rulfo, causas que no eran otras que la novedad, independencia y sutil eficacia de su nueva poética narrativa (utilizo aquí el termino poética para referirme al conjunto de procedimientos o modalidades elocutivas y compositivas que caracterizan la obra de un autor y contribuyen a la formación de su peculiar imagen del mundo y de su especificidad artística).

La primera y más importante de esas novedades era -como dejamos ya insinuado- la ausencia absoluta de la figura del autor-narrador: ni en los cuentos ni en la novela de Rulfo se hace presente el operador del proceso narrativo, a cuyo cargo corre la tarea de informar a los destinatarios de todo lo que atañe a la condición de sus personajes, que define sus acciones y emociones desde una óptica externa o superior a ellos mismos, que los juzga o califica desde la perspectiva de unos presupuestos ideológicos bien establecidos, que describe -en fin-con rasgos fácilmente identificables los espacios naturales o urbanos en que transcurre su actuación; en suma, que en los cuentos y en la novela de Rulfo, no sólo desaparece toda traza de una directa intervención del productor del discurso literario, sino que se prescinde de la función actancial del narrador -0 , si se prefiere decirlo en los términos hoy en uso, del sujeto de la enunciación enunciada $-\mathrm{y}$ son las voces de los personajes ficticios las que, de manera autónoma y quizás inopinada, ocupan la totalidad del espacio narrativo, como si éstos ya no tuvieran necesidad de ser concebidos por un autor omnisciente ni interpretados por una voz narrativa que no fuera la suya propia.

Desde la publicación de sus primeros cuentos, Rulfo fue muy consciente de la novedad y quizá del riesgo que entrańaba su nuevo modelo narrativo, $y$ así lo declaró muchos años después - sin duda acuciado por tantos y tan encontrados pareceres acerca de su obra literaria- en un brevísimo artículo publicado en 1980, «El desafío de la creación»:

En mi caso personal, tengo la característica de eliminarme de la historia, nunca cuento un cuento en que haya experiencia personal... Una de las cosas más 
difíciles que me ha costado hacer, precisamente es la eliminación del autor, eliminarme a mí mismo. Yo dejo que aquellos personajes funcionen por sí y no con mi inclusión, porque entones entro en la divagación del ensayo, en la elucubración... (16).

Y en ese mismo artículo señalaba los tres «pasos» o elementos «clave» de su poética narrativa: «el primero es crear el personaje, el segundo crear el ambiente donde ese personaje se va a mover y el tercero es cómo va a hablar ese personaje, cómo se va a expresar» (15).

Situados in medias res, como decían los antiguos, sin antecedentes ni consideraciones previas acerca de tiempos, personas y lugares, dicho todo en el presente instantáneo de su elocución, escuchamos -leyendo- el ensimismado soliloquio de los personajes creados por Rulfo y, dentro de él, el flujo de sus pensamientos, como si fuéramos nosotros quienes irrumpiéramos solapadamente en el interior de sus conciencias. He aquí el arranque de "Nos han dado la tierra»:

Después de tantas horas de caminar sin encontrar una sombra de árbol, ni una semilla de árbol, ni una raíz de nada, se oye el ladrar de los perros... Uno ha creído, en medio de este camino sin orillas, que nada habría después... Pero sí, hay algo. Hay un pueblo... (39).

No es, pues, un narrador extradiegético quien asume la función de trasmitirnos los sentimientos, acciones y reacciones de unos personajes que responden obedientemente a sus dictados, sino la inmediata «audición» de unas voces singulares que van revelándonos poco a poco la entidad de su propio ser, la naturaleza de sus afanes, la percepción de los espacios en que se mueven y el propósito de sus acciones. En «Nos han dado a tierra», el sujeto hablante («Uno») alude a la presencia de «otros» tres compañeros con los que ha "venido caminando desde el amanecer» (39) por una llanura requemada y baldía, y al cabo de mucho andar, escuchan el ladrar de unos perros y sienten en el aire «el olor del humo, y se saborea ese olor de la gente como si fuera una esperanza» (39). Agotados por ese largo caminar bajo un calor agobiante, aquellas personas han dejado de hablar entre sí, pero podemos conocer el curso de los pensamientos de una de ellas, y son precisamente los contenidos de esa actividad mental los que van manifestándose en aquellos soliloquios en que aparecen íntimamente imbricadas las imágenes del desolado espacio por el que transitan, la rememoración de cuanto les ha acontecido y la esperanza de llegar finalmente a un lugar habitado.

Pero hay más, la construcción de la entidad individual de ese sujeto de la enunciación, esto es, de la ficticia persona del hablante, de su ser y su querer, se va completando también al hilo de sus propios pensamientos; son personajes que -como ha señalado atinadamente Françoise Perus- fueron concebidos por Rulfo como «sujetos de su propia percepción del mundo» ("Camino de la vida...» 578).

Contrariamente a las expresas informaciones proporcionadas por parte de un narrador extradiegético con el fin de ponernos al tanto de las diversas circunstancias de sus personajes, sin dejar casi nada a la actividad recreadora de los destinatarios, en ese y en la casi totalidad de los relatos de Rulfo nos hallamos ante la conspicua presencia de ciertas «unidades narrativas de naturaleza integradora», los llamados indicios - una frase, una palabra- que se hallan indirecta pero estrechamente relacionados con otras unidades narrativas de mayor extensión y más plenamente informativas; la función de esos indicios consiste - de acuerdo con los planteamientos de Roland Barthes- en remitirnos implícitamente «a un carácter, un sentimiento, una atmósfera, una filosofía» (21-22), y de ahí la notable densidad semántica de aquellos componentes discursivos que el buen lector deberá saber relacionar con otras funciones narrativas portadoras de una información más explícita que le permitan descubrir la relación vinculante de aquellos esparcidos indicios con sus pertinentes correlatos y, a fin de cuentas, con la totalidad del proceso narrativo y con su entera significación. Tal sería el caso, en "Nos han dado la tierra», de la temprana mención de la esperanza que pareciera animar a los fatigados caminantes cuando creen percibir los rumores y los olores de un pueblo que, sin embargo, «está todavía muy allá. Es el viento que lo acerca» (39).

Ese tipo de ambigüedades o, por mejor decir, de densidades semánticas que incitan al lector al descubrimiento de un rico conjunto de posibilidades en la interpretación de un texto y caracterizan de manera esencial el uso poético del lenguaje, se presentan también de manera recurrente y sistemática en la narrativa rulfiana, de suerte que -en el ejemplo citado- no podríamos limitarnos a pensar que los desolados personajes de «Nos han dado la tierra» solo esperaran, al término de su agobiante camino, llegar a un pueblo apenas presentido, del mismo modo que poco antes «esperaron» inútilmente que la única gota "caída por equivocación» (40) en aquel llano desierto $\mathrm{y}$ «sin orillas» fuera el anuncio de una lluvia 
imposible: "yo sé que desde que yo era muchacho, no vi nunca llover sobre el Llano, lo que se llama llover» (40).

La esperanza de los cuatro caminantes era otra y era mucho mayor, y su verdadera naturaleza se nos irá revelando poco a poco, conforme vayamos avanzando en la recepción de aquellos soliloquios que son nuestra única puerta de entrada a los sentimientos de frustración y desengaño de unos campesinos sin tierra que se alzaron contra la explotación y el despojo de que eran objeto todos los de su clase, y ya depuestas las armas y privados de sus caballos, abrigan la esperanza de que la reforma agraria prometida por el nuevo Gobierno revolucionario los dote de sus propias parcelas cultivables. Pero no ha sido así. Un prepotente delegado de la autoridad central les hace entrega de un «llano grande» (41) que no es más que «un duro pellejo de vaca»(41), «un comal acalorado» (42) en que no crecerá ni una sola semilla, y es así como la inicial y aún no plenamente contextualizada mención de la esperanza de llegar a un pueblo a orillas del río, es indicio también de una particular situación humana y de una concreta realidad histórica del México contemporáneo: una reforma agraria cuyos desalentadores resultados son objeto de una crítica -asimismo implícita, irónica y quizá resignada- de las ominosas condiciones políticas y sociales de que también pudo ser testigo el autor: «Ésta es la tierra que nos han dado» (42).

Con todo, la presencia-implícita pero no menos patente- de aquellas realidades históricas no desvirtúa la esencial independencia artística del mundo narrativo creado por Juan Rulfo ni afecta su esencial autonomía semántica, pero vuelve a plantearnos el arduo problema en que nos coloca la inevitable «injerencia» de los «datos» de la historia en las fabulaciones literarias, particularmente en los géneros narrativos y dramáticos centrados en la representación de los azares de una vida humana. Parece evidente que los afanes que impulsan nuestros actos y alientan nuestras vidas, son -en no poca medida- producto o consecuencia de las circunstancias históricas o, como antes podía decirse, de la fortuna que nos depare esa fuerza inescrutable que llamamos destino. De modo, pues, que cuando se intenta plasmar por medios artísticos lo más significativo y perdurable de un ejemplar humano, no puede prescindirse de aquellas circunstancias políticas, sociales, ideológicas, culturales... que hayan sido determinantes en la formación de su carácter y en la prefiguración de su destino; aun en las novelas y en los dramas más declaradamente absurdos o fantásticos, reconocemos en las "personas ficticias» un sustrato que revela su entronque con alguna de aquellas «realidades» de la historia.

$\mathrm{Y}$, sin embargo, la literatura, el arte, aspiran a liberarse de las constrictivas ataduras de la historia; la suya ha de ser, si se quiere, otra historia, la historia de la singularidad y la irrepetibilidad de una "vividura» humana, como le gustaba decir a Miguel de Unamuno. De ahí también que, contrariamente a las disciplinas historiográficas y sociológicas, atenidas al exacto registro de los hechos comprobables y de sus inevitables consecuencias, las invenciones literarias aspiren a la creación de casos o ejemplos permanentes de las infinitas y no siempre predecibles posibilidades del ser, y que el único medio para lograrlo no sea otro que la proteica capacidad de nuestro lenguaje para crear otros mundos paralelos a este y, sin embargo, más reveladores y persuasivos de lo que puedan serlo las concretas realidades del mundo perecible.

Don Quijote, Peribáńez, Segismundo, Pedro Páramo, Aureliano Buendía... Son entes nacidos por mor del lenguaje y es el lenguaje quien les garantiza tanto su existencia como su pertenencia a una comunidad humana que los hizo tal cual son; de manera, pues, que si aquellas personas ficticias han logrado arraigar en nuestra imaginación y persistir en nuestra memoria ha sido también porque los lenguajes por cuyo medio se manifiestan son un expresivo trasunto de las condiciones de su origen en el otro mundo de las realidades fácticas. De ahí que sus acciones y pasiones figuradas en el espacio ilusorio de la escritura se correspondan -a su manera siempre traslaticia y simbólica-con las formas mentales y los usos verbales que les eran propios en su condición originaria, y siendo su ser y consistiendo su existir en una ilusoria ficción del lenguaje, éste haya también de manifestarse en concordancia con los usos que allá les correspondieron, y que en el universo "virtual» del arte queden asimismo representadas las formas mentales y las expresiones orales que pudieran haber sido las de sus referentes históricos.

En un estudio de mérito indudable, firmaba Walter Mignolo que Rulfo «vierte en castellano escrito relatos y decires orales supuestamente de un castellano campesino... con el propósito de ficcionalizar la oralidad mediante la escritura» (429), y que por tal razón «los narradores de los cuentos de Rulfo mantienen un registro narrativo semejante al de los personajes» (429). En efecto, las formas lingüísticas en que se expresan los héroes rulfianos son una representación literaria de los usos propios de ciertas regiones rurales de Jalisco, y ese es el medio por 
el cual se proporcionan al lector los indispensables indicios que le permitan inferir la condición étnica, social y cultural que les corresponda.

Pero en algo debo disentir de lo dicho por Mignolo, y es que el término "narrador» por él empleado, en tanto que se contrapone al de personaje, pareciera remitirse al concepto de sujeto de la enunciación enunciada -es decir, al autory no al personaje mismo o sujeto del enunciado, pero el hecho es que en los cuentos y la novela de Rulfo la totalidad del proceso narrativo se sustenta en los dichos de los personajes, cuyas modalidades de expresión no son simples traslados que de ellas podría haber hecho un autor culto, sino sus mismas voces en las que se manifiestan todas las modalidades propias de su habla coloquial. Consecuentemente, el relato que corre por cuenta de esas voces singulares ha de mantener un sustancial apego a los usos de la lengua hablada, a su léxico particular y, sobre todo, a ciertos paradigmas sintácticos y semánticos característicos de un lenguaje campesino que, en las obras de Rulfo es lo más opuesto a las superficiales transcripciones de sabor folclórico de que tanto gustaba la vieja novela costumbrista.

Por todas estas razones, debemos subrayar la capital importancia que Rulfo concedía a los variables registros de la voz humana, al grado de hacer de ella el centro generador de todas sus ficciones literarias. Su discurso de ingreso a la Academia Mexicana de la Lengua, en septiembre de 1980, versó sobre la persona y la obra de quien antes ocupó la misma silla: su entrañable amigo José Gorostiza, de quien citó este revelador pasaje de sus Notas sobre la poesía:

La afinidad entre la poesía y el canto es una afinidad congénita... En un momento cualquiera podrá relajarse o en otro ser más íntima; pero no radica en el leguaje -en el austero arsenal de la retórica, que caduca y se renueva sin cesar- sino en la voz humana misma que el hombre presta a la poesía para que, al ser proclamada, se realice en la totalidad de su perfección (Rulfo "discurso de recepción...»).

Tal era también la profunda convicción estética de Rulfo, que lo guio en la realización de una obra narrativa tan parca, exigente y ceñida como lo fue la del gran poeta de Muerte sin fin; para él como para Gorostiza es el vigor de la voz articulada -sus íntimas y personales resonancias- lo que infunde verdadera vida al lenguaje. $Y$ tal es también la que hallamos en los cuentos y la novela de Rulfo: la viva voz humana que se manifiesta en toda la perfección que sólo pueden darle sus articulaciones proclamadas en la secreta $-\mathrm{y}$ sin embargo revelada- intimidad de las conciencias.

Y para no quedarnos en la mera exposición conceptual de las modalidades elocutivas características de la obra de Rulfo, veamos algún ejemplo en «Nos han dado la tierra»:

Ahorita son algo así como las cuatro de la tarde. Alguien se asoma al cielo, estira los ojos hacia donde está colgado el sol y dice: -Son como las cuatro de la tarde... Faustino dice: -Puede que llueva... Y pensamos: «Puede que sí» (39-40).

Con el uso del «ahorita» -anotaba García Icazbalceta en su Vocabulario de mexicanismos- "aún se estrecha más el tiempo», y es una locución adverbial que empleamos constantemente en nuestro español mexicano, lo mismo que las expresiones «algo así», "puede que sí», "son algo así como...» para indicar una cierta dubitación del hablante respecto de su anterior aserto. Pero el uso de los verbos «estirar» como acción atribuida a la mirada y de «estar colgado" para referirse a la fijeza del sol en el cenit, son acepciones que no podrían haber sido registradas por un lexicógrafo, ya que no forman parte de ningún "castellano campesino" estabilizado por el uso, sino que son resultado de la creación o el descubrimiento por parte del hablante de una analogía semántica, que estando directamente vinculada con su experiencia cotidiana, es -sobre todo- una forma de comprensión del mundo: ¡cómo potenciar el esfuerzo de la mirada sino «estirando» al máximo los ojos, y cómo significar la intensísima fuerza del sol sino como si -al igual que una lámpara incandescenteestuviera colgado e inmóvil sobre la cabeza de los caminantes?

Son estos apenas unos casos que ejemplifican la intuitiva y certerísima capacidad de Juan Rulfo para crear un lenguaje afín a la personalidad y al origen de sus criaturas literarias, como lo son también las descripciones del llano como un "pellejo de vaca» o un "comal acalorado", expresiones de carácter metafórico asimismo fundadas en el contexto rural y doméstico al que pertenecen los personajes, y que se constituyen como formas paradigmáticas que les permiten alcanzar la comprensión del mundo desde la perspectiva de su propia experiencia personal:

$\mathrm{Y}$ en este comal acalorado quieren que sembremos semillas de algo, para ver si algo retoña y se levanta. Pero nada se levanta de aquí. Ni zopilotes. Uno los ve 
allá cada y cuando, muy arriba, volando a la carrea, tratando de salir lo más pronto posible de este blanco terregal endurecido, donde nada se mueve y por donde uno camina como reculando (42).

Estos ejemplos del estilo «indicativo», que es un recurso esencial en la poética narrativa de Juan Rulfo, aún podrían completarse con diversas variantes de índole inductiva de aquella manera de significación implícita por medio de la cual se convoca al lector a expandir el significado de una misma frase o lexema según los contextos en que aparezca, como es el caso de la esperanza arriba considerado, por medio de la cual se conmina al lector a recurrir a sus propios saberes sobre el mundo con el fin de alcanzar una más plena y matizada interpretación del texto. En el fragmento arriba citado, la mención de los zopilotes que van «volando a la carrera», tratando de salir cuanto antes del «blanco terregal endurecido», son imágenes eidéticas, dotadas de un fuerte carácter icónico y simbólico, que expanden y completan la dramática representación de aquel llano desierto en que no es posible encontrar ninguna esperanza de vida ${ }^{4}$.

Viendo esto así, podría afirmarse que las representaciones literarias del habla campesina en las obras de Rulfo son mucho más que un mero proceso de ficcionalización dispuesto por un autor culto de los decires populares de una comunidad o una región determinadas, toda vez que su léxico, tono, modalidades elocutivas y cognitivas han sido determinantes para la construcción de una visión del mundo que les resulte consustancial; de ahí también que el discurso narrativo de Rulfo se corresponda con los modos de ser, pensar, sentir y expresarse propios de la entidad social y espiritual a la que se adscriben aquellas personas ficticias y, a consecuencia de esto, que aun en los casos en que llegara a actualizase en el texto la función de un autor-narrador extradiegético -como algunos críticos han creído advertir en ciertos segmentos de Pedro Paramo- su estilo no podría ser distinto del que corresponde al estilo oral y mental de los personajes. En «Nos han dado la tierra» la descripción de los lugares en que se mueven los

4. En el artículo «Pedro Páramo: los laberintos de la memoria» traté con más detenimiento la función de las «imágenes eidéticas» en la novela de Rulfo. Puede consultarse en: Juan Rulfo, Toda la obra. Claude Fell, coordinador. Colección Archivos, México, 1992, y también en mi libro Construcción y sentido de la realidad simbólica. Cervantes, Rulfo, García Márquez. UNAM, Dirección de Literatura y DGE Equilibrista, México, 2015. caminantes no pertenece, obviamente, a la voz de un narrador extradiegético, sino que es parte del mismo soliloquio del personaje que los va percibiendo, como si -al contario de sus compañeros a quienes el calor les ha "traspasado el sombrero» (43) y ya no tienen «la cabeza en su lugar» (43)- hiciera un gran esfuerzo por mantener el dominio de su conciencia prestando atención a los ruidos y los olores que anuncian la cercanía de un pueblo, y marcan así un significativo contrapunto -implícita y sabiamente graduado por Rulfo- con la árida soledad de «La tierra que nos han dado":

Por encima del río, sobre las copas verdes de las casuarinas, vuelan parvadas de chachalacas verdes. Eso también es lo que nos gusta.

Ahora los ladridos de los perros se oyen aquí, junto a nosotros, y es que el viento que viene del pueblo retacha en la barranca y la llena de todos sus ruidos (44).

Y como ya sea tiempo de llegar a alguna concusión, diríamos que en los relatos de Rulfo quedó instaurada y perfecta desde sus mismos inicios una nueva poética o modelo de ficción literaria fundado en un género de fidelidad muy distinta a la que nos tenía habituados la novela monológica, realista y documental; esa nueva fidelidad no respondía ya al propósito de dar un testimonio -quizá animado por los recursos del arte- de las peripecias de una lucha civil, de la exaltación o condena de sus protagonistas, del triunfo o fracaso de una ideología o de un proyecto social, sino a otra clase de realidades: la realidad de las formas verbales y mentales por las que se manifiesta en sus obras lo más entrañable, singular, profundo y permanente del ser del hombre en ese su tiempo mexicano.

\section{Bibliografía}

Azuela, Mariano. Obras escogidas. Novelas y cuentos. Prólogo de María Azuela de Sáenz. Promexa Editores, Méxíco, (1979): 260 y ss.

BARTHES, Roland. «Introducción al análisis estructural de los relatos». Silvia Niccolini (comp.). El análisis estructural. Buenos Aires: Centro Editor de América Latina, Buenos Aires, 1977.

Blanco Aguinaga, Carlos. "Realidad y estilo de Juan Rulfo». Revista Mexicana de Literatura, 1, (1955): 59-82.

Mignolo, Walter. «Escribir la oralidad: la obra de Juan Rulfo en el contexto de las literaturas del "tercer 
mundo"». Claude Fell (ed.): Juan Rulfo, toda la obra. Madrid: Archivos, 1992: 429-445.

Pascual Buxó, José. «Introducción. Juan Rulfo: construcción y sentido de lo real imaginario", a Juan Rulfo, el arte de narrar, de Françoise Perus. México: Universidad Nacional Autónoma de México-Universidad Nacional de Colombia, 2012: 9-19.

Pascual Buxó, José. "Juan Rulfo y los laberintos de la memoria». Federico Campbell (ed.). La ficción de la memoria: Juan Rulfo ante la critica. México: Universidad Nacional Autónoma de México-Era, 2003: 272-282.

Pascual Buxó, José. «Pedro Páramo: los laberintos de la memoria». Claude Fell (ed.). Juan Rulfo, Toda la obra. Claude Fell, coordinador. Colección Archivos, México, 1992.

Pascual Buxó, José. "Rulfo y lo "real imaginario"», Revista de la Universidad de México, 92, (octubre, 2011): 22-29.

Pascual Buxó, José. Construcción y sentido de la realidad simbólica: Cervantes, Rulfo y García Márquez. México: Universidad Nacional Autónoma de México,
Coordinación de Difusión Cultural, Dirección de Literatura: DGE Equilibrista, 2015.

Perus, Françoise. «Camino de la vida: Nos han dado la tierra, de Juan Rulfo». LXIX, 204, (2003): 577-598.

Perus, Françoise. Juan Rulfo, el arte de narrar. México: Dirección de Literatura UNAM, Fundación Juan Rulfo, Editorial RM, 2012.

Rulfo, Juan. «El desafío de la creación». Revista de la Universidad de México, XXV, 1980.

Rulfo, Juan. «Macario», Pan, 6, 1945.

Rulfo, Juan. «Nos han dado la tierra». Pan, 2, 1945.

Rulfo, Juan. Juan Rulfo: discurso de recepción como número, en su ingreso a la Academia Mexicana. México: Academia Mexicana de la Lengua, Instituto Cultural Cabañas, Instituto Luis Silva, 1987. Recuperado de http://www.academia.org.mx/SesionPublica\&id=83.

Rulfo, Juan, El llano en llamas. Editorial RM, Fundación Juan Rulfo, México, 2014.

Vital, Alberto, María Esther Guzmán y Stella Cuéllar (ed.). 60 años de el Llano en llamas: reflexiones académicas. México: UNAM, Instituto de Investigaciones Filológicas, 2015. 